\title{
A morfologia social de Robert Hertz
}

DoI

http://dx.doi.org/10.11606/ 2179-0892.ra.2017.137328

\author{
Pedro Paulo Pimenta \\ - Universidade de São Paulo / São Paulo, SP, Brasil \\ $\boldsymbol{\nabla}$ pedronamba@gmail.com
}

HERTZ, Robert. 2016. Sociologia religiosa e folclore. Tradução de Guilherme João de Freitas Teixeira, Petrópolis, Vozes, 267 pp.
A publicação em língua portuguesa de uma coletânea de escritos de Robert Hertz é um evento que merece ser celebrado por todos os interessados na história do pensamento sociológico e antropológico. Os artigos reunidos em Sociologia religiosa e folclore, cuidadosamente traduzidos por Guilherme João de Freitas Teixeira, incluem os dois clássicos pelos quais Hertz tornou-se conhecido: "Contribuição para um estudo sobre a representação coletiva de morte" (1907), e "A preeminência da mão direita. Estudo sobre a polaridade religiosa" (1909), além de um estudo sobre o culto a São Besso no interior da França (1913), uma coletânea de contos e provérbios - reunidos pelo autor no front na Primeira Grande Guerra, onde viria a falecer, em 1915-e uma resenha publicada postumamente em 1917. Por ser baseada num volume da PUF surgido em 1970, que reproduz, por sua vez, aquele organizado por Mauss em 1928, esta coletânea não inclui o curto ensaio "Socialisme et dépopulation", tampouco o estudo inacabado, concluído por Mauss, intitulado "Le peché et l'expiation dans les sociétés primitives". Ambos podem ser encontrados no volume Oeuvres publiés (Garnier Classiques, 2104). Esse conjunto de textos, embora exíguo, foi o suficiente para que o nome de Hertz se firmasse entre os grandes da sociologia francesa. Ao menos é essa a opinião de Evans-Pritchard, ele mesmo um herdeiro reticente dessa tradição'.

A releitura desses escritos vigorosos tem muito a ensinar, e sem dúvida há diferentes maneiras de lê-los. Uma delas, que proporemos aqui, parte de uma afirmação feita logo no início do estudo "Sobre a representação coletiva da morte". "Para os biólogos", diz Hertz, "a morte não é um dado simples e evidente, mas um problema a ser abordado por uma investigação científica”; é
1 "The historical value oh Hertz's writings is that they are a representative example of the culmination of two centuries of development of sociological thought in France, from Montesquieu to Durkheim and his pupils" (Evans-Pritchard, 1981: 172). 
um evento que "não se resume aos fenômenos fisiológicos: ao acontecimento orgânico, acrescenta-se um conjunto complexo de crenças, emoções e atos que Ihe conferem um caráter próprio" de uma sociedade a outra (: 17). Hertz traçar com essas palavras uma fronteira entre os domínios de investigação do biólogo, de um lado, e do sociólogo, de outro. O "acontecimento orgânico", o "fenômeno fisiológico", como quer que seja chamado, adquire feições peculiares, quando se leva em conta como os homens se lidam com ele em diferentes circunstâncias. "Observa-se a vida que se extingue, mas esse fato é expresso em uma linguagem particular", que dá ao fenômeno "objetivo" (aspas minhas) uma determinação simbólica (: 17). Na vida social, o fisiológico, o orgânico e o biológico são como que condensados nas práticas rituais, por sua vez determinadas por exigências incidentes à situação particular de cada sociedade.

Tudo parece claro: para se afirmar como ciência, a sociologia precisa se contrapor à biologia, identificando o modo particular como um fenômeno natural é absorvido na teia das relações sociais. Essa distinção é como que consagrada pelo estilo de Hertz, que a tradução soube transpor para o português. Sua prosa límpida e analítica serve à descrição de fatos e à sua conjugação num quadro, em que eles são como que apreendidos pelo olhar do leitor-que, diga-se de passagem, não tem nenhuma dificuldade para acompanhar a sua concatenação. Ao que tudo indica, teríamos aí um discípulo do positivismo francês, tradição inaugurada por Condillac ainda no século XVIII: a percepção como quadro de representações confusas, a prosa como instrumento de sua análise e reorganização segundo marcas comuns, estipuladas pelo observador, o tableau como lugar natural da exposição sintética dessa operação de deslindamento das percepções. Feito isso, e fixado o objeto, pode-se compará-lo a outros do mesmo gênero e chegar a algo como uma teoria geral.

Não me parece que o ensaio "Sobre a ideia coletiva de morte" desminta essa conclusão. Mas eu tampouco diria que ele a corrobora por inteiro, e seria um absurdo reduzir Hertz a um mero positivista-qualquer que seja o significado que se atribua a essa expressão. Pois a delimitação do território da sociologia em relação ao da biologia não implica, para Hertz, uma separação estanque entre os fatos da vida social e o substrato biológico sobre o qual eles se constituem, tampouco uma relação linear de causa e efeito entre duas instâncias hierarquicamente dispostas uma em relação à outra. Quanto a isso, é interessante relembrar o ensinamento de Mauss, de que nosso autor é tributário.

O ensaio sobre "As variações sazonais das sociedades esquimós", publicado em 1906, é um claro exemplo da aplicação, aos estudos de sociologia e antropologia, da categoria de "morfologia social", cunhada por Durkheim². Para Mauss, essa categoria é nada menos que a base de uma ciência

2 Limito-me aqui a remeter o leitor à introdução de Nathan Schlanger ao volume Techniques, technologie et civilisation (2012). 
que estuda, não somente para descrevê-lo, mas também para explicá-lo, o substrato material das sociedades, ou a forma que elas adquirem ao se estabelecer num solo, o volume e a densidade da população, a maneira como esta se distribui assim como o conjunto das coisas que servem como sede da vida coletiva (Mauss, 2012: 144).

A morfologia social é uma ciência da organização social, compreendida a partir das condições materiais que determinam certo número de práticas coletivas, característico de um grupo. Mauss faz questão de distingui-la da Antropogeografia, centrada no solo, componente "telúrico" visto como o substrato material determinante das práticas sociais tomadas em conjunto, como se essa circunstância não fosse uma, dentre muitas a serem consideradas no estudo da "forma material dos agrupamentos humanos", onde "o fator telúrico deve ser posto em relação com o meio social em sua totalidade e complexidade" (Mauss, 2012: 149-150). Trata-se, portanto, no estudo dos diferentes agrupamentos de esquimós, de identificar variações circunstanciais recorrentes, incidentes à organização das práticas sociais, variações essas determinadas pelas condições que o meio impõe à efetivação das técnicas humanas, em concomitância com a recorrência de certos padrões, que permitem remeter esses grupos a uma mesma forma geral de sociedade. Essa espécie de sociologia divide-se, assim, em morfologia geral e morfologia particular, ou "sazonal". Pode-se dizer, dessa ciência, que ela é um estudo de práticas sociais tomadas como atividades que se desenrolam em meio a condicionantes naturais, que as determinam, por um lado, e, por outro, são transformadas por elas.

Parece-me que Hertz tem em vista algo assim. Com esta diferença: se Mauss estuda as relações entre o meio e a sociedade, interessam a Hertz aquelas entre o organismo e o meio, enquanto mediadas pelas práticas sociais. Inversamente, as práticas sociais são o princípio a partir do qual a experiência será dividida em social e biológica.

No ensaio "Sobre a preeminência da mão direita" encontra-se, a título de preâmbulo, uma consideração similar à que comentei a propósito do ensaio "Sobre a ideia coletiva de morte". Para compreender as razões desse fenômeno e explica-lo como signo de uma "polaridade religiosa" (ou seja, tratá-lo como linguagem), Hertz se vê obrigado, mais uma vez, a acertar contas com a biologia. Começa reconhecendo que de fato parece haver aí uma determinante anatômica. Que se verifique um "desenvolvimento mais considerável, no ser humano, do hemisfério cerebral esquerdo, que, como se sabe, enerva os músculos do lado oposto", parece ser prova suficiente de que a preferência pela mão direita antecede as determinações sociais: "o privilégio da mão direita estaria fundamentalmente na estrutura assimétrica dos centros nervosos, cuja causa, seja ela 
qual for, é evidentemente orgânica". Estaria provada, com isso, a verdade desta tirada, atribuída ao médico e anatomista Paul Broca: "somos destros relativamente à mão por sermos canhotos no cérebro" (: 98). Sem propriamente negar que haveria aí uma "correlação", Hertz questiona a hierarquização entre dois fenômenos cuja observação conjunta não oferece ao cientista nenhuma indicação a respeito de qual deles seria a causa, qual o efeito. "O que nos impediria de inverter essa proposição e dizer: somos canhotos relativamente ao cérebro por sermos destros na mão?", ele se pergunta, com uma pitada de humor. Não seria o enervamento muscular uma causa do desenvolvimento acentuado do hemisfério esquerdo do cérebro? Não se trata, com isso, de suprimir a ideia de que esse hemisfério teria, na conformação natural do ser humano, um volume ligeiramente maior, e de que haveria, portanto, uma tendência ao uso da mão destra de preferência à canhota. Hertz não nega o valor da anatomia; mas tem o cuidado de distingui-la da fisiologia: "se fizermos abstração dos efeitos produzidos pelo exercício e pelos hábitos adquiridos, a superioridade fisiológica do hemisfério esquerdo é algo de tão reduzido que, no máximo, pode determinar uma ligeira preferência em favor do lado direito" (: 98). Em vez de tomar sem mais a configuração anatômica como causa da função fisiológica, não seria melhor ver nesta última um princípio capaz de incidir sobre aquela? Ora, se é assim, e se a hipertrofia dos músculos da mão é capaz de "ensinar" o cérebro a dar preferência absoluta ao uso da direta em detrimento da esquerda, então se segue que o adestramento, como fenômeno cultural (de origem religiosa, como se verá ao longo do ensaio), incide no corpo precisamente porque a forma deste é determinada, em última instância, pelas atividades que ele exerce, para as quais tem, bem entendido, uma aptidão. "O privilégio instituído pelos homens vem acrescentar-se ao privilégio natural”, isto é, vem confirmá-lo, não por um impulso natural, mas por uma determinação al heia à constituição do organismo como sistema autônomo.

Nesses termos, Hertz propõe algo que equivale, teoricamente, à supressão de toda dicotomia entre Natureza e Cultura, ao mesmo tempo em que reconhece na biologia uma ciência que, embora distinta da sociologia, é indispensável a esta como complemento. Essa constatação, que permite superar a oposição instituída no início do ensaio "Sobre a representação coletiva da morte", decorre de uma exigência imposta à compreensão do próprio fenômeno em questão:

não é, portanto, por ser frágil e incapaz, que a mão esquerda é negligenciada, mas o contrário é que corresponde à verdade. Essa mão é submetida a uma verdadeira mutilação, que não deixa de ser bem característica, pois diz respeito à função, e não à forma externa do órgão, poisé fisiológica e não anatômica (:100-101). 
A distinção entre anatomia e fisiologia, no interior do que antes era simplesmente denominado por Hertz como biologia e oposto à sociologia, desdobra-se no domínio da própria análise. Se voltarmos ao ensaio "Sobre a representação coletiva da morte", veremos ali o uso pontual, em momentos cruciais da exposição, quando a compreensão de um fenômeno numa sociedade em particular exige a comparação com fenômenos similares em outras, da categoria de homologia, que Hertz toma de empréstimo à anatomia comparada, onde ela é utilizada juntamente com a categoria de analogia.

Para compreender o significado desses conceitos, não é preciso remontar aqui às suas origens, nos escritos de Georges Cuvier e de Étienne Geoffroy de Saint-Hilaire, tampouco à sua utilização posterior, por Richard Owen³. No momento em que Hertz escreve, a distinção está consagrada no interior da língua francesa, como se percebe pelas entradas dedicadas a esses termos no dicionário Littré - publicado entre 1863 e 1877, no intervalo que separa os ensaios de Hertz dos artigos dos naturalistas a que nos referimos. "Analogia: relação, similitude entre diversas coisas diferentes. Existe analogia entre o cavalo e o asno", assim como existe analogia anatômica entre as mãos dos humanos e as nadadeiras dos cetáceos, por exemplo. "Homologia: relação entre órgãos considerados idênticos, qualquer que seja sua forma, em razão das conexões e da estrutura". Se a analogia é uma relação de similaridade aparente e fortuita; a homologia é uma relação de identidade estrutural e necessária, a despeito do que possam indicar as similaridades aparentes.

Ouçamos agora Hertz, no estudo "Sobre a representação coletiva da morte":

Do nosso ponto de vista, há uma homologia rigorosa entre a exposição do cadáver nos ramos de uma árvore, tal como a praticam as tribos do centro da Austrália; ou no interior da casa dos vivos, como é o costume encontrado entre alguns Papuas e povos Bantus; ou em cima de uma plataforma erguida para esse fim, como é o costume dos polinésios e de numerosas tribos indígenas da América do Norte; ou, enfim, o enterro provisório, observado em particular na maior parte dos índios da América do Sul (: 33-34).

É uma passagem vertiginosa: vê-se aí nada menos que a elevação do funcionalismo a um estruturalismo, mediante o uso sustentado da comparação como método de apreensão da lógica constitutiva das práticas sociais (já sabemos, pela leitura do ensaio sobre a preponderância da mão direita, que a constituição dessas práticas se dá sobre um substrato biológico determinado: 0 corpo). É então que Hertz explica:

Todas essas formas diversas de sepultura provisória - que, em uma classificação
3 Para o tratamento teórico desses conceitos em tais autores, ver Stéphane Schmitt (2006) 
tecnológica, deveriam sem dúvida figurara sob rubricas especiais-são para nós equivalentes: elas têm o mesmo objetivo, ou seja, oferecer ao morto uma residência temporária enquanto espera o termo da dissolução natural do corpo, momento em que restam apenas as ossadas (: 34$)$.

A identificação de uma funcionalidade nos mais diversos rituais mortuários opera aí como um princípio de desmistificação da compreensão das "sociedades primitivas", cujo "exotismo" é reduzido a uma ilusão, substituída pela lógica rigorosa que governa essas diferentes adaptações circunstanciais ao meio-essas variações morfológicas, para falarmos com Mauss. Estabelecida uma homologia de fundo, um princípio geral de organização, compreendem-se as variações morfológicas, ou de desenvolvimento dos rituais fúnebres, e pode-se proceder com segurança a uma taxonomia das técnicas específicas.

A esta altura, cabe perguntar: seria então o método sociológico da "escola francesa" um herdeiro direto da anatomia comparada? Estariam as ciências sociais, desde o bojo de seu processo de constituição, a reboque das ciências naturais? Não nos cabe aqui decidir essa questão, que, de resto, foi abordada de maneira rigorosa e instigante em estudos como os de Judith Schlanger (1971) e Dominique Guillo (2003). Mas cabe observar que, para Hertz, não se trata de reducionismo. A projeção do esquema função-ordem, encontrado em Cuvier, na fronteira entre natureza e cultura, traçada na superfície e na estrutura do corpo humano, o uso da homologia como categoria de análise de representações empíricas, o método de análise e síntese por comparação, tudo isso indica que, para ele, a sociologia é tão irredutível à biologia quanto dependente dela. $\mathrm{E}$ não poderia ser diferente, quando o corpo humano, no qual natureza e a cultura convergem, desponta como objeto por excelência de ambas essas ciências. É um objeto capcioso, irredutível a uma determinação completa, e, portanto, um fato limitador de toda ambição de compreensão totalizante da experiência. Em outras palavras, a dissolução da dicotomia natureza-cultura, substituída pela confluência, no corpo humano, do social e do biológico, assinala o ponto para além do qual o estabelecimento de relações de causa e efeito se torna um exercício puramente arbitrário.

Nos limites desta resenha, dificilmente caberia a extrapolação-entretanto sugerida pelo viés de leitura adotado-segundo a qual o corpo seria, na sociologia de Hertz, o princípio de articulação, divisão e hierarquização da experiência humana: um princípio de inteligibilidade, verdadeiro foco transcendental a partir do qual se institui um sentido para fatos que, como a morte, são em si mesmos desprovidos de significado. A certa altura do ensaio "Sobre a preponderância da mão direita", Hertz reconhece: "Somos, portanto, obri- 
gados a buscar na estrutura do organismo a linha divisória que dirige o fluxo benfazejo de graças sobrenaturais em direção ao lado direito" (: 98). Frase notável, que me parece delinear todo um programa de pesquisa, que, salvo engano, foi desenvolvido, em diferentes direções, por autores como Mauss (em As técnicas do corpo, 1934) e Evans-Pritchard (em Feitiçaria, oráculos e magia entre os Azande, 1937). A confecção do sentido não deixa de ser uma operação técnica, em que a sensação e o raciocínio se combinam para fabricar uma imagem social do corpo, por incitação das circunstâncias, ditadas pelas necessidades do grupo, porém sempre de acordo com as condicionantes anatômicas e fisiológicas que tornam isso possível nos indivíduos, enquanto espécie. Éa "Iinha divisória" a que se refere Hertz, que dirige a intencionalidade humana para as regiões que, no substrato orgânico, são mais aptas a acolhê-la de modo a devolvê-la ao meio, devidamente transformadas, ou simbolizadas. A última palavra, a esse respeito, cabe ao próprio Hertz:

Evitemos ver, nesse último recurso à anatomia, uma contradição ou concessão. Uma coisa é explicar a natureza e a origem de uma força, outra é determinar o ponto ao qual ela se aplica. As leves vantagens fisiológicas da mão direita são apenas a oportunidade de uma diferenciação qualitativa, cuja causa jaz, para além do indivíduo, na constituição da consciência coletiva. Uma assimetria corporal quase insignificante é suficiente para dirigir representações contrárias, todas elas já formadas, num sentido e no outro. Em seguida, graças à plasticidade do organismo, a coação social acrescenta e incorpora aos dois membros opostos as qualidades de força e fraqueza, de destreza e falta de jeito, as quais parecem emanar, no adulto, espontaneamente da natureza (:120).

Pedro Paulo Pimenta é Graduado em Filosofia pela Universidade de São Paulo (1994), mestre (1997) e doutor (2002) pela mesma instituição, onde leciona desde 2005. Dedica-se a estudos na área de Filosofia Moderna, com especial ênfase em autores do Século XVIII.

\section{REFERÊNCIAS BIBLIOGRÁFICAS}

EVANS-PRITCHARD, Edward

1981 A history of anthropological thought. Londres, Faber \& Faber. 
GUILLO, Dominique

2003 Les Figures de l'organisation. Sciences de la vie et sciences sociales au XIXe siècle.

Paris, PUF.

MAUSS, Marcel

2012 "Essai sur les variations saisonnières des sociétés eskimos". In

Techniques, technologie et civilization. Paris, PUF.

SCHLANGER, Judith

1971 Les Métaphores de l'organisme. Paris, Vrin.

SCHLANGER, Nathan

2012 "Une Technologie engagée. Marcel Mauss et l'étude des techniques dans les sciences sociales". In MAUSS, Marcel. Techniques, technologie et civilization. Paris, PUF.

SCHMITT, Stéphane

2006 Aux Origines de la biologie moderne. L'Anatomie comparée d'Aristote à la théorie de l'évolution. Paris, Belin. 